\title{
Demagnetization Analysis of Ferrite Permanent Magnets in Dual Rotor Wind Power Generator
}

\author{
Peifeng $\mathrm{Xu}^{1}$, Kai Shi ${ }^{1}$ and $\mathrm{Yi} \mathrm{Zhu}{ }^{2}$ \\ ${ }^{1}$ School of Electrical and Information Engineering, Jiangsu University, Zhenjiang, \\ China. \\ ${ }^{2}$ Jiangsu Province Special Equipment Safety Supervision Inspection Institute- \\ Branch of Wuxi, China. \\ xupeifeng80@ujs.edu.cn, shikai80614@163.com,yishuang1009@163.com
}

\begin{abstract}
This paper analyzes the demagnetization performance of the ferrite Permanent Magnets in the dual rotor radial flux permanent magnet generator. Two different partial demagnetization mechanisms in the DRRFPM generator are modeled and demonstrated. The $2 D$ finite element analysis (FEA) is employed to accurately analyze the distribution of demagnetization. The 2D FEA results for the proposed DRRFPM generator verify the validity of the partial demagnetization model. The performance degradation induced by demagnetization is evaluated for the proposed generator based on the 2D FEA results. This research reveals the most vulnerable region of the magnet to irreversible demagnetization in the DRRFPM generator.
\end{abstract}

Keywords: partial irreversible demagnetization, ferrite permanent magnet, dual rotor radial flux permanent magnet generator, finite element analysis

\section{Introduction}

The permanent magnet (PM) machines have been widely used for their numerous advantages such as small volume, light weight, simple structure, high torque density, low loss, high efficiency, and no additional power supply due to the magnet field excitation. Most up-to-date PM machines use rare earth magnetic materials, namely neodymium iron boron $(\mathrm{NdFeB})$ grades, because of their high remanence and coercivity values. However, the use of $\mathrm{NdFeB}$ materials should be reduced, because the cost of $\mathrm{NdFeB}$ materials has increased significantly over the last several years and there is an increasing concern about the stable supply of the raw material supply for $\mathrm{NdFeB}$. As a result, there is a high demand for electrical machines using ferrite magnets. The design of a PM machine using ferrite permanent magnet materials is actively studied [1-4].

Due to the structure of double rotors and dual air-gaps, the dual rotor radial flux permanent magnet (DRRFPM) machine using NdFeB magnets can significantly improve the torque density and efficiency [5]. When using ferrite magnets, it is demonstrated that the DRRFPM machines can even reach the performance of the traditional PM machines using NdFeB magnets [6-7]. The design and performance of the DRRFPM machine using ferrite PMs is studied in [7]. But when the DRRFPM machine using ferrite magnets operates in cold weather, the ferrite magnets in the rotors will be affected by a demagnetizing field, resulting in a serious deterioration of machine performance, such as a decrease in output torque and power. Meanwhile, it is highly possible for the ferrite magnets to be demagnetized due to the external demagnetizing field generated by peak winding currents. Therefore, it is necessary to consider the demagnetization effects in the DRRFPM generator.

The reported results mainly focused on the demagnetization behaviors of the surface and interior PM machines [8-9], particularly under faulty conditions [10-11]. The 
demagnetization analyses of some other types of PM machines were also reported, such as tubular permanent magnet machine [12], ferrite-assisted synchronous reluctance machine [13], and flux-switching permanent magnet machine [14-15]. However, the irreversible demagnetization characteristics of the DRRFPM generator were rarely studied. In these literatures, the demagnetization behavior under various operating conditions was evaluated, but the partial demagnetization mechanism was not considered.

In order to understand the partial irreversible demagnetization characteristics of ferrite magnets in the DRRFPM generators, this paper investigates the causes and influences of partial irreversible demagnetization. The research clearly reveals the most vulnerable region to irreversible demagnetization in the magnets of the DRRFPM machine. The method developed in this paper provides an effective tool for assessing the partial irreversible demagnetization risk of magnets in the DRRFPM machines.

\section{Mechanism of Irreversible Demagnetization in the DRRFPM Generator}

The brief specifications of the proposed DRRFPM generator are shown in Table 1 and the corresponding demagnetization analysis model is shown in Figure 1. The generator consists of two concentric rotors and a cup stator sandwiched between the two rotors. The ferrite permanent magnets are surface-mounted on the surface of the inner and outer rotors, and are radially polarized in the opposite direction, namely north-north $(\mathrm{N}-\mathrm{N})$ type. The materials of the stator and rotor cores are non-oriented steel sheets. The magnet material used in the generator is Hitachi NMF-3B.

Demagnetization can be complete, or partial. Partial demagnetization can be symmetric or asymmetric. Dependent on the fault severity, demagnetization can be reversible or irreversible. It has been verified that the irreversible demagnetization happens in magnets under transient states instead of steady states [16-17]. The irreversible demagnetization occurs when the flux density of the magnet is lower than the knee point value of the demagnetization curve. To evaluate demagnetization, the flux density of the magnet should be calculated.

Table 1. Specifications of the DRRFPM Generator

\begin{tabular}{ccc}
\hline \hline Specifications & Values & Unit \\
\hline Rated Power & 1.5 & $\mathrm{~kW}$ \\
\hline Rated Frequency & 50 & $\mathrm{~Hz}$ \\
\hline Rated Speed & 375 & $\mathrm{rpm}$ \\
\hline Rated Voltage & 150 & $\mathrm{~V}$ \\
\hline Stator Outer Diameter & 200 & $\mathrm{~mm}$ \\
\hline Stator Inner Diameter & 86 & $\mathrm{~mm}$ \\
\hline Stack Length & 200 & $\mathrm{~mm}$ \\
\hline Air Gap Length & 0.5 & $\mathrm{~mm}$ \\
\hline Winding type & back-to-back toroidally wound \\
\hline \hline
\end{tabular}



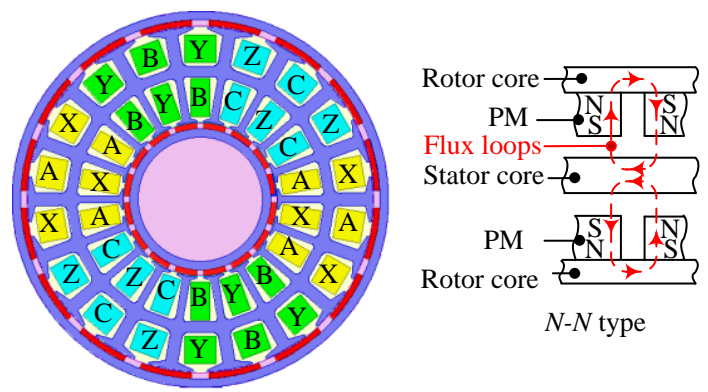

$N-N$ type

\section{Figure 1. Configuration of the Proposed DRRFPM Generator}

The flux density components in the magnet of the DRRFPM generators are timedependent. Because the polarized direction in the DRRFPM generator is radial, the circumferential flux density does not influence the demagnetization property. So the lowest flux density along the radial direction should be kept above the knee point in order to keep the magnet away from irreversible demagnetization, as shown in expression (1). Using this criterion, it can be determined whether the magnet has been demagnetized,

$$
\begin{aligned}
& B_{r \min 1,2}(r, \theta)=\min \left[B_{r 1,2}(r, \theta)\right] \\
& B_{r \text { min } 1,2}(r, \theta)>B_{\text {knee }}
\end{aligned}
$$

where $B_{r 1,2}(r, \theta)$ is the radial flux density component in the inner/outer magnet, $B_{\text {knee }}$ is flux density at the knee point of the magnet.

The mechanism of partial demagnetization in the DRRFPM generator can be divided into two categories, that is, the self-demagnetization of the magnets and the influence of the armature reaction field. It should be noted that all the analysis in this section is under the assumption that the rotors are rotating in the counterclockwise direction.

\subsection{Air-Gap Permeance}

When the interval between two adjacent magnets aligns with the stator slot, the flux path between the stator and inner/outer rotor is shown in Figure 2 (because of the symmetry, only half of the fluxes of two adjacent magnets are given).

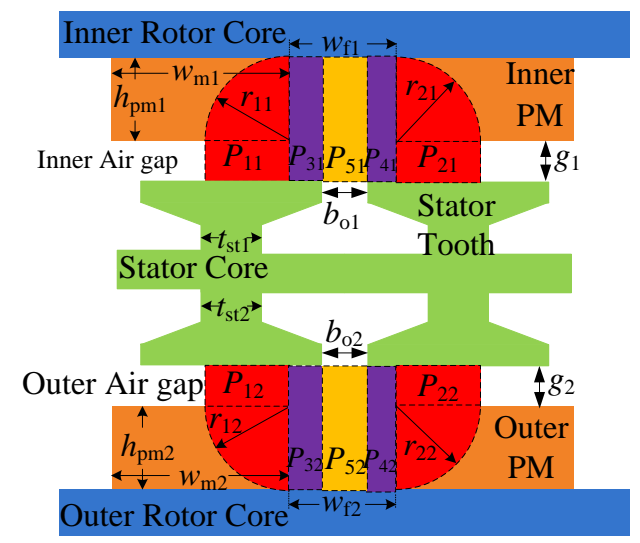

\section{Figure 2. The Air-Gap Permeances of the DRRFPM Generator}

To investigate the partial demagnetization of the ferrite magnets, the permeance of each flux path should be calculated. Flux paths $\mathrm{P}_{11}, \mathrm{P}_{12}, \mathrm{P}_{21}$, and $\mathrm{P}_{22}$ go through the magnet and can result in demagnetization. Flux paths $\mathrm{P}_{31}, \mathrm{P}_{32}, \mathrm{P}_{41}, \mathrm{P}_{42}, \mathrm{P}_{51}$, and $\mathrm{P}_{52}$ do not go through the magnet, and thus will not cause demagnetization. The magnet material has a relative permeability near to 1 , so it can be treated as air. In Figure $2, r_{11}, r_{12}, r_{21}$, and $r_{22}$ are radiuses of the flux paths $\mathrm{P}_{11}, \mathrm{P}_{12}, \mathrm{P}_{21}, \mathrm{P}_{22}, w_{\mathrm{m} 1,2}$ is the width of the inner/outer magnet, 
$t_{\mathrm{st1}, 2}$ is the width of inner/outer stator tooth, $w_{\mathrm{f} 1,2}$ is the interval width between the inner/outer magnets, $g_{1,2}$ is the length of inner/outer air-gap, $b_{01,2}$ is the length of inner/outer slot opening and $l_{\mathrm{e}}$ is the effective length of the generator.

The permeances of any small section of thickness $\mathrm{d} r_{11}$ and $\mathrm{d} r_{12}$ in the flux path $\mathrm{P}_{11}$ and $\mathrm{P}_{12}$ can be expressed by

$$
\mathrm{d} p_{11}=\frac{\mu_{0} l_{\mathrm{e}} \mathrm{d} r_{11}}{g_{1}+0.5 \pi r_{11}}, \quad \mathrm{~d} p_{12}=\frac{\mu_{0} l_{\mathrm{e}} \mathrm{d} r_{12}}{g_{2}+0.5 \pi r_{12}}
$$

Hence, the permeances of flux path $\mathrm{P}_{11}, \mathrm{P}_{12}, \mathrm{P}_{21}$, and $\mathrm{P}_{22}$ can be calculated by

$$
\begin{aligned}
& p_{11}=p_{21}=\int_{0}^{w_{\mathrm{m} 1} / 2} \frac{\mu_{0} l_{\mathrm{e}}}{g_{1}+0.5 \pi r_{11}} \mathrm{~d} r_{11}=\frac{2 \mu_{0} l_{\mathrm{e}}}{\pi} \ln \left[\frac{4 g_{1}+\pi w_{\mathrm{m} 1}}{4 g_{1}}\right] \\
& p_{12}=p_{22}=\int_{0}^{w_{\mathrm{m} 2} / 2} \frac{\mu_{0} l_{\mathrm{e}}}{g_{2}+0.5 \pi r_{12}} \mathrm{~d} r_{12}=\frac{2 \mu_{0} l_{\mathrm{e}}}{\pi} \ln \left[\frac{4 g_{2}+\pi w_{\mathrm{m} 2}}{4 g_{2}}\right]
\end{aligned}
$$

The permeances of flux path $\mathrm{P}_{31}, \mathrm{P}_{32}, \mathrm{P}_{41}$, and $\mathrm{P}_{42}$ can be expressed by

$$
\begin{aligned}
& p_{31}=p_{32}=\frac{\mu_{0} l_{\mathrm{e}}\left(w_{\mathrm{f} 1}-b_{\mathrm{o} 1}\right) / 2}{g_{1}} \\
& p_{41}=p_{42}=\frac{\mu_{0} l_{\mathrm{e}}\left(w_{\mathrm{f} 2}-b_{02}\right) / 2}{g_{2}}
\end{aligned}
$$

The permeances of flux path $\mathrm{P}_{51}$ and $\mathrm{P}_{52}$ will be

$$
p_{51}=\frac{\mu_{0} l_{\mathrm{e}} b_{\mathrm{o} 1}}{g_{1}}, \quad p_{52}=\frac{\mu_{0} l_{\mathrm{e}} b_{\mathrm{o} 2}}{g_{2}}
$$

Using the air-gap permeance expressions, the mechanism of self-demagnetization and demagnetization to armature reaction can be evaluated.

\subsection{Self-Demagnetization}

To investigate the self-demagnetization, the DRRFPM generator is studied under no load operation. Figure 3 shows the magnetic equivalent circuit of one pole pair under no load operation when the interval between two adjacent magnets aligns with the stator slot (because of the similarity, only the inner part is drawn). The magnets are divided into several parts. $F_{\mathrm{pm} 11}, F_{\mathrm{pm} 21}, F_{\mathrm{pm} 31}$, and $F_{\mathrm{pm} 41}$ are the magneto motive forces (MMFs) of each part of the magnets, and $R_{\mathrm{pm} 11}, R_{\mathrm{pm} 21}, R_{\mathrm{pm} 31}$, and $R_{\mathrm{pm} 41}$ are the magnetic reluctances of each part of the magnets. $R_{g 11}$ and $R_{g 21}$ are the reluctances of the air gap between magnets and stator tooth, $R_{g 31}$ and $R_{g 41}$ are the reluctances of the air gap between the rotor core and stator tooth, and $R_{g 51}$ is the air gap reluctance between the rotor core and slot. $R_{s t 11}, R_{s t 21}$ $R_{s t 31}$, and $R_{s t 41}$ are the reluctances inside the stator teeth. $R_{r 1}$ is the reluctance of the inner rotor core.

At the rotor position shown in Figure 3, a large amount of flux $\Phi_{11}$ and $\Phi_{21}$ will flow through the loop shown in dotted line, which will lead to negative $\Phi_{31}$ and $\Phi_{41}$. The flux densities in the part 3 and 4 will be opposite to their magnetization direction. Therefore, these parts may be partially irreversibly demagnetized.

This analysis illustrates that the magnets near the air gap are vulnerable to selfdemagnetization in the condition shown in Figure 3. When the rotor rotates, the selfdemagnetization effect will change because flux $\Phi_{11}$ or $\Phi_{21}$ will be less dominant. The self-demagnetization only happens to a small fraction of the magnets. 


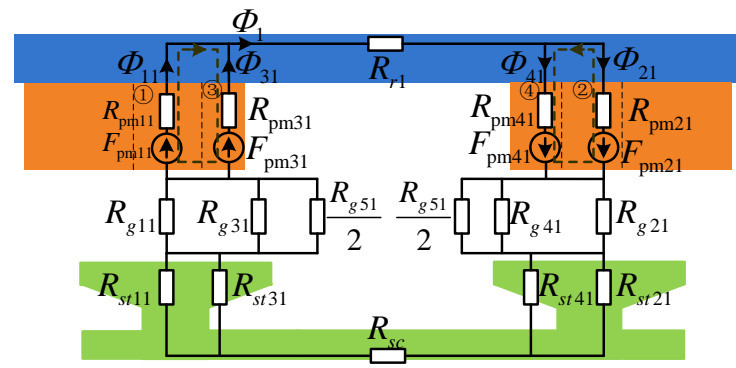

\section{Figure 3. Magnetic Equivalent Circuit of One Pole Pair under No Load Operation When Two Magnets Interval Aligns With the Stator Slot}

\subsection{Demagnetization Due To Armature Reaction}

To study the demagnetization in the permanent magnet due to armature reaction, the DRRFPM generator is studied under the condition that the magnets are not magnetized. The armature current tends to create a magnetic field with its axis $90^{\circ}$ away from the axis of the magnet flux. Figure 4 shows the magnetic equivalent circuit of one pole pair, where $F_{a 1}$ and $R_{a 1}$ are the MMF and reluctance of the winding respectively. Similar to the self-demagnetization, the flux produced by $F_{a 1}$ will lead to negative $\Phi_{11}, \Phi_{21}, \Phi_{31}$ and $\Phi_{41}$. The flux densities in the magnets will be opposite to their magnetization direction. Therefore, these parts may be partially irreversibly demagnetized.

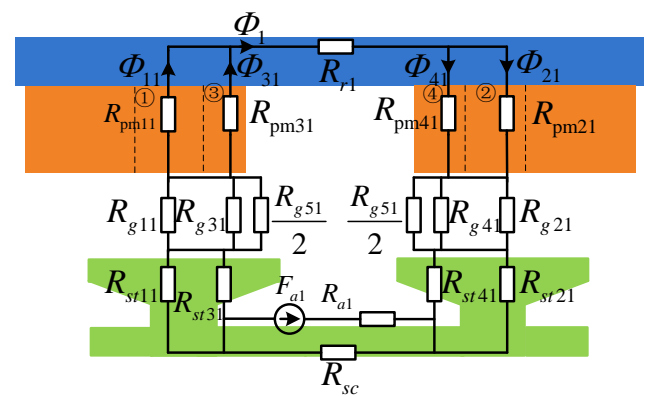

Figure 4. Magnetic Equivalent Circuit of One Pole Pair with Armature Winding Energized and Magnet Not Magnetized When Two Magnets Interval Aligns With the Stator Slot

\subsection{Overall Demagnetization}

Under the normal operation of the DRRFPM generator, the self-demagnetization and armature reaction demagnetization are superimposed on each other. The effect of this armature reaction field is to shift the location of the magnetic field away from the magnetic axis, which results in the total field at one edge of the field pole being increased and decreased at the other edge. The flux distribution is altered but the total flux is unchanged since the increased flux density will be balanced by the correspondingly decreased value in the linear material. To achieve better accuracy, irreversible partial demagnetization characteristics of DRRFPM generator will be analyzed using 2D FEA. 


\subsection{Validation by Finite-Element Analysis}

The 2D FEA is used to validate the mechanism of partial irreversible demagnetization. The demagnetization $\mathrm{BH}$ curves of NMF-3B at different temperatures are shown in Figure 5 . At $20{ }^{\circ} \mathrm{C}$, the flux density of knee point is $B_{\text {knee }}$ $=0.16 \mathrm{~T}$, the coercive force and the remanent magnetic flux density of ferrite magnets are $190 \mathrm{kA} / \mathrm{m}$ and $0.41 \mathrm{~T}$, respectively. In Figure 5, it can also be seen that it is more difficult for the ferrite magnet to be demagnetized as the temperature increases.

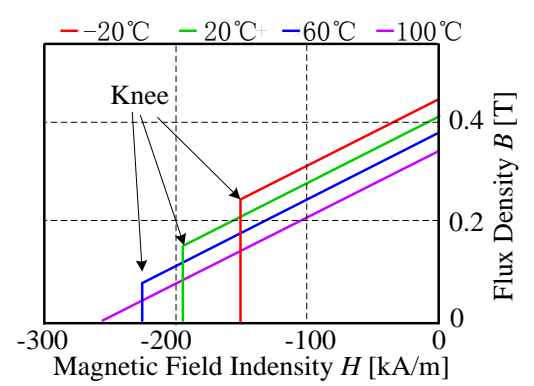

Figure 5. Demagnetization Curve of Ferrite Magnet (NMF-3B)

The FEA simulation results are shown in Figure 6 and Figure 7 respectively. Figure 6 shows the flux distribution under no load operation, where the arrows represent the corresponding flux direction. It can be seen that the flux in the ovals are not completely in radial direction, which is the result of the self-demagnetization. Figure 7 shows the flux distribution when the armature winding is excited and the magnets are not magnetized. The direction of flux lines is opposite to the magnetization.

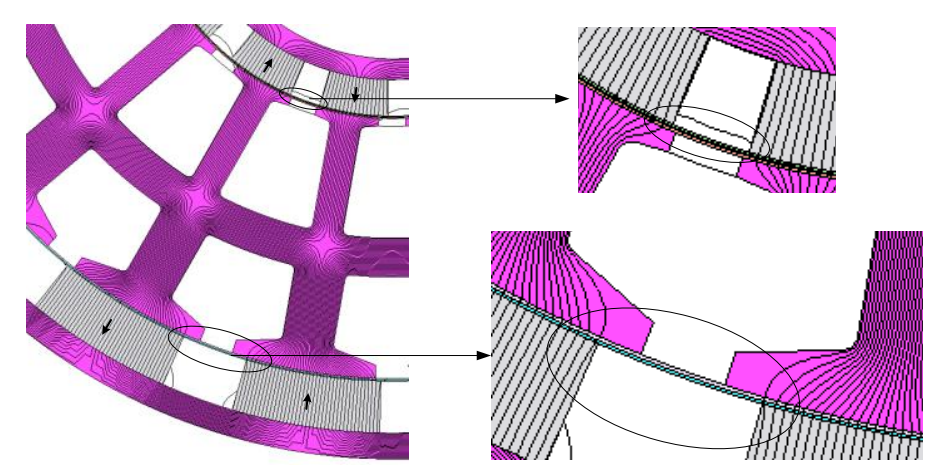

Figure 6. Flux Distribution under No Load Operation 


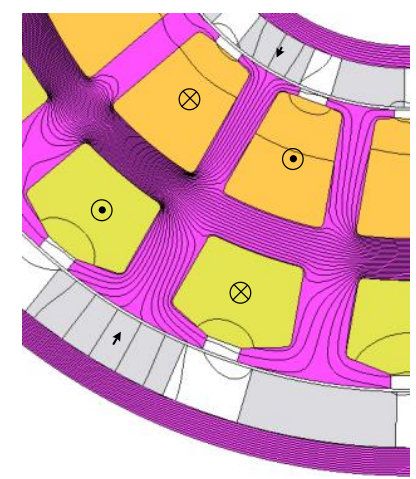

\section{Figure 7. Flux Distribution When Armature Winding Is Energized and Magnets Are Not Magnetized}

\section{Evaluation of PM Demagnetization}

To illustrate and validate the mechanism of partial demagnetization in the ferrite magnets of the DRRFPM generator, the machine is simulated using JMAG-Designer under worst case at an ambient temperature of $-20{ }^{\circ} \mathrm{C}$.

\subsection{Demagnetization Characteristics}

To analyze the irreversible demagnetization characteristics, the magnets shown in Figure 8 are selected. All the other magnets have the same demagnetization characteristics as the selected ones. Five different locations in the inner and outer magnets are respectively chosen. Four of these selected locations are at each corner of the ferrite magnet, and the fifth location is in the middle. Points $\mathrm{C}_{1,2}$ and $\mathrm{D}_{1,2}$ are near to the air gap.

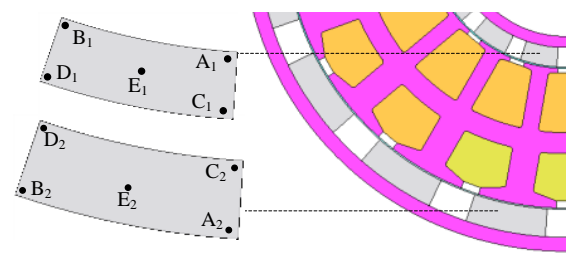

Figure 8. Ferrite Magnets and Different Locations for Partial Irreversible Demagnetization Analysis in the DRRFPM Generator

The resulting flux densities under no load operation at $-20{ }^{\circ} \mathrm{C}$ during one electrical cycle in the radial direction, which is the magnetization direction of the inner/outer ferrite magnet, are shown in Figure 9.

In Figure 9, the flux densities of the points A1, B1, E1 A2, B2, C2, D2, and E2 can be kept above the demagnetization limit, while the flux densities of points $\mathrm{C} 1$ and D1 go below the limit. That is to say, the inner ferrite magnets are much easier to be demagnetized than the outer ones. It can also be seen that in the inner magnet, the flux densities of points $\mathrm{C} 1, \mathrm{D} 1$ are much lower than those of point $\mathrm{A} 1, \mathrm{~B} 1$, and in the outer magnet, the flux densities of points $\mathrm{C} 2$, D2 are much lower than that of point A2, B2. This proves that the part near the air gap suffers the most severe irreversible demagnetization threat, due to the superposition of the self-demagnetization. 


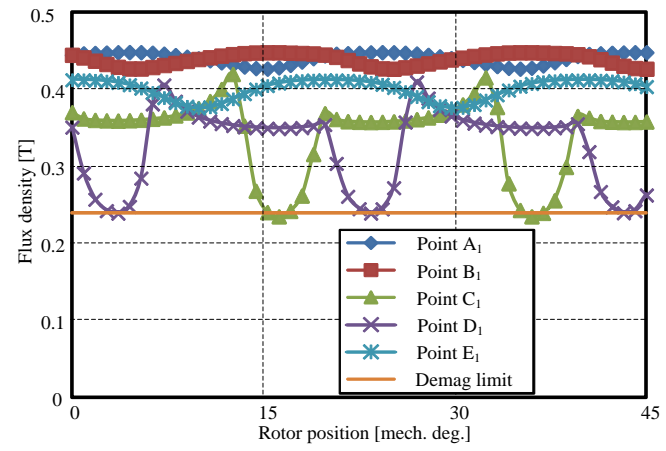

(a) Points of the inner magnet

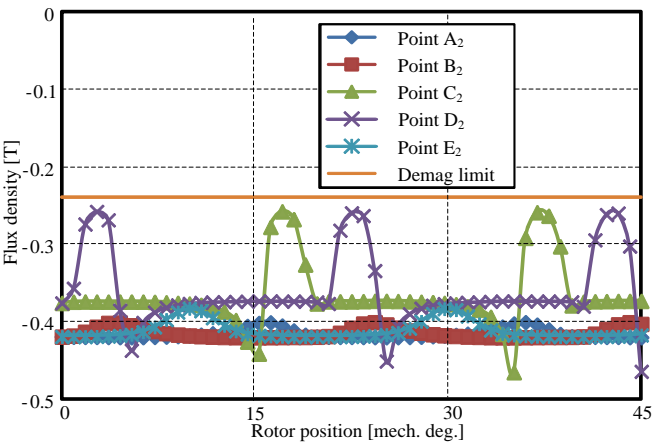

(b) Points of the outer magnet

\section{Figure 9. Flux Densities (Radial Direction) In Different Locations of the Magnets}

Figure 10 shows the partial irreversible demagnetization of the inner and outer magnets. The regions in the ovals in Figure 10 (a) and (c) show the demagnetized region of the inner and outer magnets. Figure 10 (b) and (d) clearly show that the flux density direction of the ferrite magnets in the demagnetization region is different to its magnetization, but it is still at the normal direction in the other parts of the magnet. In Figure 10, it can be found that the demagnetization region in the inner magnet is larger than that in the outer magnet, and the inner magnet is easier to be demagnetized than the outer one. This is because the radius of the outer magnet is larger than that of the inner one, and the volume of the outer magnet is correspondingly larger.
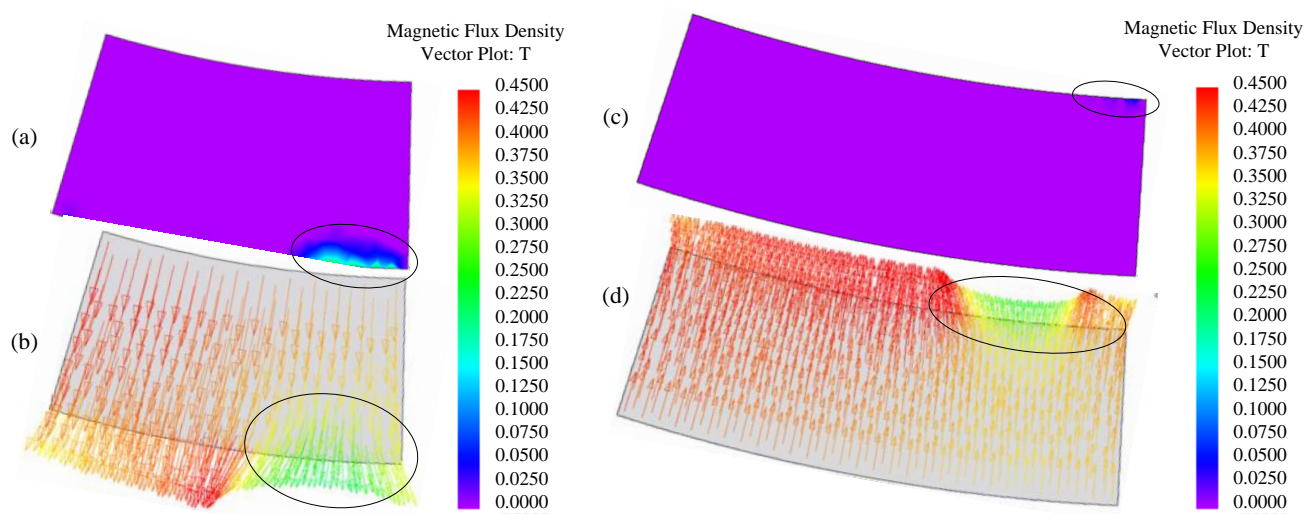

Figure 10. Partial Demagnetization of the Magnets. (A) Demagnetization Region in the Inner Magnet (Shown In Blue). (B) Flux Density Vector of the Inner Magnet. (C) Demagnetization Region in the Outer Magnet. (D) Flux Density Vector of the Outer Magnet

Figure 11 shows the demagnetization ration distribution of the magnets in the DRRFPM generator under rated operation at $-20{ }^{\circ} \mathrm{C}$. The demagnetization shown here is the irreversible demagnetization from going over the knee point, and indicates that the magnets properties have worsened. 


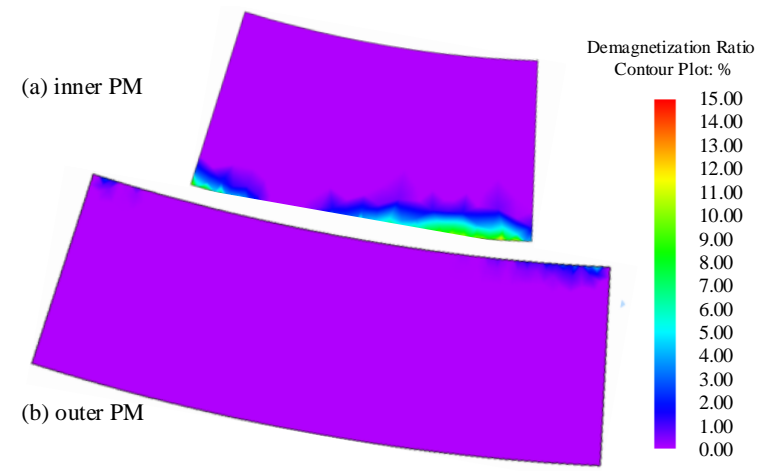

Figure 11. Demagnetization Ratio of the Magnets in the DRRFPM Generator under Rated Operations At -20 ${ }^{\circ} \mathrm{C}$. (A) Inner PM. (B) Outer PM

\subsection{Performance Degradation Due To Partial Irreversible Demagnetization}

The partial irreversible demagnetization of magnets results in a reduction of the air-gap flux density, the stator winding flux linkage, and hence the output torque and power. To investigate the performance degradation due to partial irreversible demagnetization, it is assumed that the demagnetized region shown in Figure 10 has been totally demagnetized (i.e., it is treated as air space).

The performance degradation after partial irreversible demagnetization is shown in Figure 12-13. Figure 12 shows the phase voltage waveforms under rated operation. Figure 13 shows the flux-linkage waveforms, and Figure 14 shows the instantaneous torque of the inner and outer part. It can be seen that phase voltage, magnetic flux linkage and average output torque have all been reduced due to the partial irreversible demagnetization.

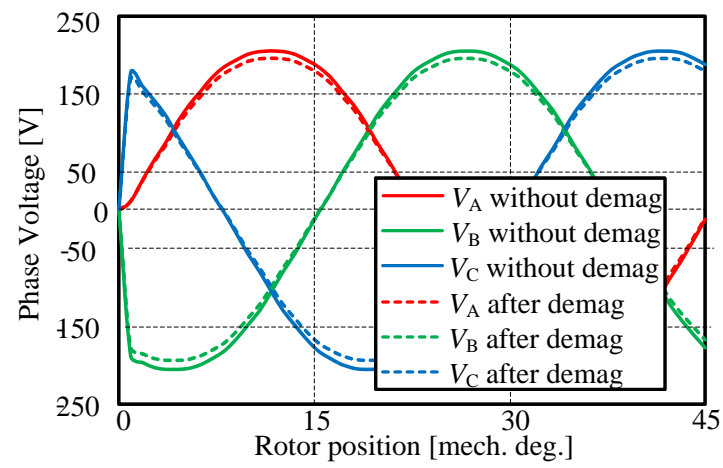

Figure 12. Phase Voltage Waveforms under Rated Operation without Demagnetization and After Demagnetization 


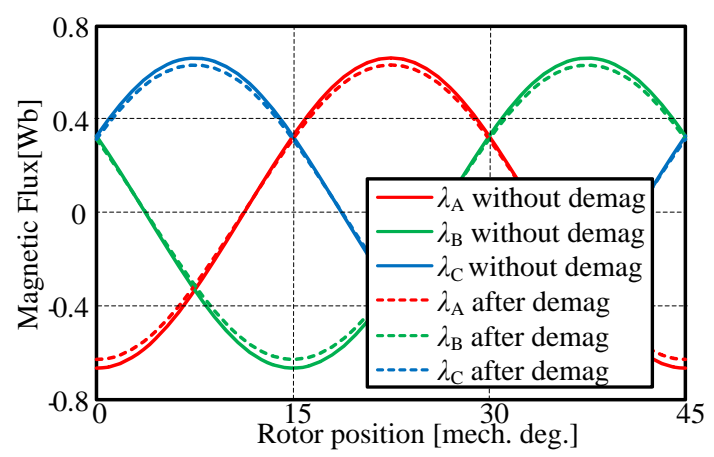

Figure 13. Magnetic Flux-Linkage Waveforms under Rated Operation without Magnetization and After Demagnetization

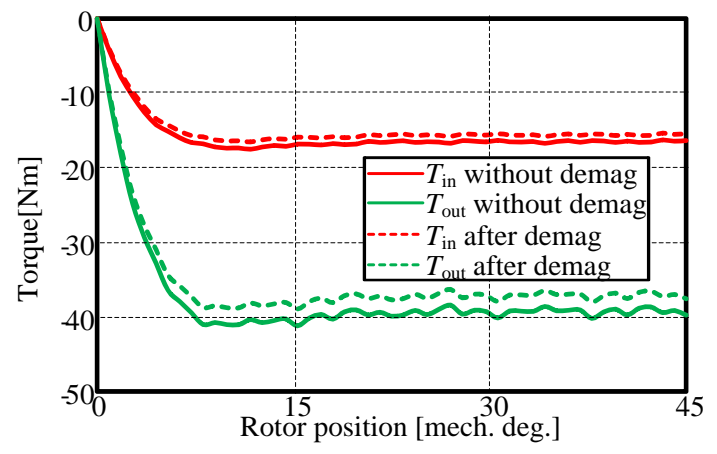

Figure 14. Torque Waveforms of the Inner and Outer Part under Rated Operation without Demagnetization and After Demagnetization

It is worth noting that the performance degradation shown in Figure 12-14 represents the worst case condition $-20{ }^{\circ} \mathrm{C}$, because the demagnetized portion of the magnets has been treated as air. In reality, the magnet temperature will be higher than $-20{ }^{\circ} \mathrm{C}$ for the sake of the winding heat, and the demagnetized magnet will work on minor recoil lines instead of being totally demagnetized. Under this circumstance, the performance degradation will be slightly better compared with the worst case condition.

\section{Discussion}

The partial irreversible demagnetization of DRRFPM generator has been verified via FEA. The FEA approach is capable and very convenient to help verify the mechanism of partial demagnetization, and it can be used for the initial design. The accuracy of FEA approach for demagnetization analysis was confirmed by experimental results in [18-19].

Even though the DRRFPM generator has a strong tendency of partial demagnetization near to the air gap, the majority part of the permanent magnets in DRRFPM generator is not subjected to any significant demagnetizing MMFs during normal operation.

Optimization considering multiple machine parameters can be used in the design of DRRFPM generator to minimize the partial reversible demagnetization and to maximize the output performance. 


\section{Conclusion}

This paper investigates the partial irreversible demagnetization characteristics of the ferrite magnets in the DRRFPM generators. Two different partial demagnetization mechanisms in the DRRFPM generators have been modeled and demonstrated. The 2-D FEA results have verified the validity of the proposed partial demagnetization model. The performance degradation of the ferrite DRRFPM generator after partial irreversible demagnetization has been investigated.

The research clearly reveals that the most vulnerable region in the ferrite magnets of the DRRFPM generator to irreversible demagnetization. The method developed in this paper provides an effective tool for assessing the partial irreversible demagnetization risk of magnets in the DRRFPM generator.

\section{Acknowledgements}

This work was supported in part by the National Natural Science Foundation of China under grant 51407085, the Postdoctoral Science Foundation of China under Award No. 2015M571685, the grant from the Priority Academic Program Development of Jiangsu Higher Education Institution and Jiangsu University Senior Talents Special Project under award 13JDG111.

\section{References}

[1] S. Morimoto, S. Ooi, Y. Inoue and M. Sanada, "Experimental Evaluation of a Rare-Earth-Free PMASynRM with Ferrite Magnets for Automotive Applications", IEEE Trans. Industrial Electronics, vol. 61 , no. $10, \mathbf{( 2 0 1 4 )}$

[2] I. Boldea, L. N. Tutelea, L. Parsa and D. Dorrell, "Automotive Electric Propulsion Systems with Reduced or No Permanent Magnets: An Overview”, IEEE Trans. Industrial Electronics, vol. 61, no. 10, (2014).

[3] S. Ooi, S. Morimoto, M. Sanada and Y. Inoue, "Performance Evaluation of a High-Power-Density PMASynRM with Ferrite Magnets", IEEE Trans. Industry Applications, vol. 49, no. 3, (2013).

[4] S. M. Jang, H. J. Seo, Y. S. Park, H. Park and J. Y. Choi, "Design and Electromagnetic Field Characteristic Analysis of $1.5 \mathrm{~kW}$ Small Scale Wind Power Generator for Substitution of Nd-Fe-B to Ferrite Permanent Magnet", IEEE Trans. Magnetics, vol. 48, no. 11, (2012).

[5] S. Mohammadi and M. Mirsalim, "Analytical Design Framework for Torque and Back-EMF Optimization and Inductance Calculation in Double-Rotor Radial-Flux Air-Cored Permanent-Magnet Synchronous Machines”, IEEE Trans. Magnetics, vol. 50, no. 1, (2014).

[6] R. Qu, M. Aydin and T. A. Lipo, "Performance Comparison of Dual-Rotor Radial-Flux and Axial-Flux Permanent- Magnet BLDC Machines", Proceedings of the Electric Machines and Drives Conference, Madison, WI, USA, (2003).

[7] P. Xu, X. Liu, K. Shi and F. Xiao, "Design and analysis of a dual-rotor radial flux permanent-magnet generator", Proceedings of the 17th International Conference Electrical Machines and Systems, Hangzhou, China, (2014).

[8] P. Sergeant and A. P. M. Van den Bossche, "Influence of the Amount of Permanent-Magnet Material in Fractional-Slot Permanent- Magnet Synchronous Machines”, IEEE Trans. Industrial Electronics, vol. 61, no. 9, (2014).

[9] K. C. Kim, K. Kim, H. J. Kim and J. Lee, "Demagnetization analysis of permanent magnets according to rotor types of interior permanent magnet synchronous motor", IEEE Trans. Magnetics, vol. 45, no. 6, (2009).

[10] S. S. Moosavi, A. Djerdir, Y. AIT. Amirae and D. A. Khabud, "Demagnetization Fault Investigation In Permanent Magnet Synchronous Motor", Proceedings of the 5th Power Electronics, Drive Systems and Technologies Conference, Tehran, Iran, (2014).

[11] B. M. Ebrahimi, and J. Faiz, "Demagnetization Fault Diagnosis in Surface Mounted Permanent Magnet Synchronous Motors", IEEE Trans. Magnetics, vol. 49, no. 3, (2013).

[12] J. Wang, W. Wang, K. Atallah and D. Howe, "Demagnetization assessment for three-phase tubular brushless permanent-magnet machines", IEEE Trans. Magnetics, vol. 44, no. 9, (2008).

[13] A. Vagati, B. Boazzo, P. Guglielmi and G. Pellegrino, "Design of Ferrite-Assisted Synchronous Reluctance Machines Robust Toward Demagnetization”, IEEE Trans. Industry Applications, vol. 50, no. 3, (2014). 
[14] A. Fasolo, L. Alberti and N. Bianchi, "Performance comparison between switching-flux and IPM machine with rare earth and ferrite PMs", Proceeding of the International Conference on Electrical Machines, Marseille, France, (2012).

[15] J. D. McFarland, T. M. Jahns and A. M. El-Refaie, "Demagnetization performance characteristics of flux switching permanent magnet machines", Proceedings of the International Conference on Electrical Machines, Berlin, Germany, (2014).

[16] M. Obata, S. Morimoto, M. Sanada and Y. Inoue, "Performance of PMASynRM with Ferrite Magnets for EV/HEV Applications Considering Productivity”, IEEE Trans. Industry Applications, vol. 50, no. 4, (2013).

[17] B. M. Ebrahimi and J. Faiz, "Demagnetization Fault Diagnosis in Surface Mounted Permanent Magnet Synchronous Motors", IEEE Trans. Magnetics, vol. 49, no. 3, (2013).

[18] Y. S. Lee, K. T. Kim and J. Hur, "Finite-element analysis of the demagnetization of IPM-type BLDC motor with stator turn fault", IEEE Trans. Magnetics, vol. 50, no. 2, (2014).

[19] S. Ruoho, J. Kolehmainen, J. Ikaheimo and A. Arkkio, "Demagnetization testing for a mixed-grade dovetail permanent- magnet machine", IEEE Trans. Magnetics, vol. 45, no. 9, (2009).

\section{Authors}
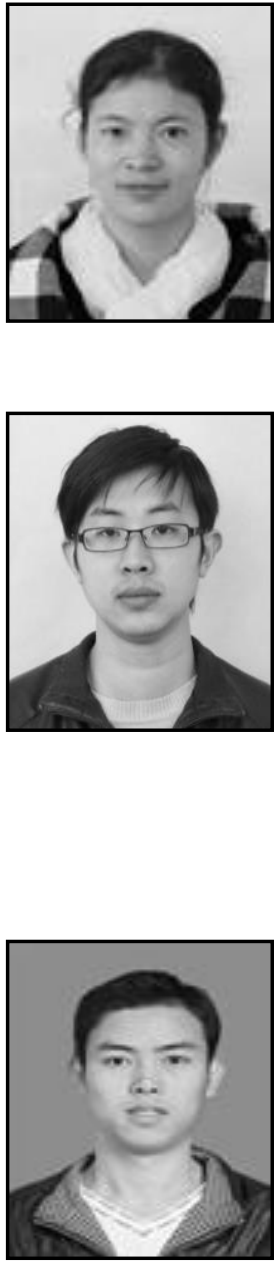

Peifeng Xu, she was born in Nantong, China, in 1980. She received her B.S. and M.S. degrees in Electrical Engineering from Jiangsu University, Zhenjiang, China, in 2002 and 2005, respectively. Since 2002, she has been working at the School of Electrical and Information Engineering, Jiangsu University, Zhenjiang, China. Since 2007, she has been a Lecturer at Jiangsu University. Her current research interests include the design and control of highefficiency wind power generators.

Kai Shi, he was born in Suzhou, China, in 1980. He received his B.S. degree in Automation and his M.S. degree in Power Electronic and Power Transmission from Jiangsu University, Zhenjiang, China, in 2002 and 2005, respectively. He received his Ph.D. degree in Power Electronic and Power Transmission from Nanjing University of Aeronautics and Astronautics, Nanjing, China, in 2012. Since 2002, he has been with the School of Electrical and Information Engineering, Jiangsu University. Since 2013, he has been an Assistant Professor in Jiangsu University. His current research interests include wind power generator control, grid-connected control, and control strategies of low-voltage ride through.

Yi Zhu, she was born in Suzhou, China, in 1988. He received his B.S. degree in Mathematics and Applied Mathematics and his M.S. degree in Control Theory and Control Engineering from Jiangsu University, Zhenjiang, China, in 2008 and 2011, respectively. Since 2011, he was a researcher in automatic control department of Institute of Research of Iron \& Steel Jiangsu province (Shasteel). Since 2013, he has been an inspector in Jiangsu Province Special Equipment Safety Supervision Inspection Institute-Branch of Wuxi. His current research interests include wind power generator control and application of Internet of things in elevator. 